\title{
First steps on technological and genetic improvement of European abalone (Haliotis tuberculata) based on investigations in full-sib families
}

\author{
Valérie Roussel $^{1}$, Julien Charreyron ${ }^{1}$, Sylvain Labarre ${ }^{2}$, Alain Van Wormhoudt ${ }^{1}$, Sylvain Huchette ${ }^{2}$ \\ ${ }^{1}$ MNHN, UMR 7208 BOREA, Station de Biologie Marine, Concarneau, France \\ ${ }^{2}$ France Haliotis, Plouguerneau, France \\ Email: vroussel@mnhn.fr \\ Received 24 July 2013; revised 20 August 2013; accepted 28 August 2013 \\ Copyright (C) 2013 Valérie Roussel et al. This is an open access article distributed under the Creative Commons Attribution License, \\ which permits unrestricted use, distribution, and reproduction in any medium, provided the original work is properly cited.
}

\section{ABSTRACT}

The European abalone Haliotis tuberculata is of economical importance in Europe, and recently in France where most of the consumed abalones remained wild animals fished on the coast. Recently, the creation of hatcheries allowed the production of cultured animals, and aquaculture is in progress. To optimize selective breeding programs, different studies were performed on adults and on their progenies. First, ten adult families, assumed to be bi-parental and produced in 2007 were analyzed. As these families were developed at the beginning of the hatchery production, the parentage of the individual necessitated to be tested. The progenies parentage assignment was done by using eight microsatellite DNA loci. In fine, the heritability was estimated from the analysis of variance of seven full-sib families which include from 23 to 27 progenies. Heritability estimate was the higher for length, width and weight $(0.37,0.29$ and 0.40 respectively). A high correlation was also shown between these heritable traits which can be useful during animal breeding. Shell color traits were also analyzed, using image treatment procedure. Two traits were selected according to the global color of the shell: red color and hue. The distribution of these traits evidenced a polygenic genetic control of shell color and measure of heritability evidenced a high to medium value for red color $(\mathrm{Cr})$ and Hue $(\mathrm{H})(\mathbf{0 . 3 3}$ and 0.20 respectively). No correlation was shown between growth and this parameter. In a second time, juveniles families produced in $\mathbf{2 0 1 0}$ were studied from parents issued of the first selection. A correlation between size and density at juvenile stage was established but a statistical analysis demonstrated, by using density as co-variable a significant effect of family on size. In these conditions, growth is highly heritable (0.74). This study is a first step toward the use of genetic markers for selection, but also a step toward the breeding improvement of European abalone.

Keywords: European Abalone; Microsatellite; Heritability; Morphological Traits; Shell Color Traits; Juvenile

\section{INTRODUCTION}

Abalones are marine gastropods living worldwide in temperate or tropical waters [1] and appreciated for its comestible foot. Because of their great economical importance, the first cultures of Asian abalone began in the 1950's [2]. Researches on hatchery methods started in Japan in the 1960's and later in California and Taiwan in the 1960's, Korea, France and Ireland in the 1970's, New Zealand and Australia in the 1980's [3] and South Africa in the 1990's [4]. Two ways can be considered for the improvement of abalone aquaculture, including technological and genetic approaches $[5,6]$. The first one comprises the hatchery conditions (temperature, food for larvae or adult, cages size and management) and the second would be based on Markers Assisted Selection (MAS). The technical improvement of hatchery conditions started in the 90's for tropical abalone, with a first step related to fertilization and larval care, and a second step related to the survival and growth of post-settlement larvae [2]. These investigations are occuring for other genus of abalones $[7,8]$, but no studies were devoted to European abalones. Concerning the second way of improvement, the genetic way, the first studies started in the 2000's for indo-pacific abalones [9,10], and the most advanced investigations are done on the Pacific abalone (Haliotis discus hannai) and the blacklip abalone (Haliotis 
rubra) for which genetic linkage maps are already available [11-14]. In Europe, abalone farming still remains new. Since the 1980's, land based recirculation grow-out techniques were imported and adapted from South Africa or New Zealand to start an industry in Ire- land [15], but with little success so far. In the 2000's, land based and sea based grow-out systems were developed in Western France yielding better results.

A study concerning the optimization of MAS programs evidenced the high interest of such techniques to improve genetic gain and cost benefits for Australian abalone [16]. But to date, no programs of MAS were developed on temperate abalones. The distribution of European Abalone Haliotis tuberculata spreads in a large temperate region, from the Morocco Atlantic coast to the English Channel and the Mediterranean sea $[17,18]$. The chromosome number of European abalone is $2 \mathrm{n}=28$, whereas the Indo-Pacific and North-Pacific species have a higher chromosome number with $2 \mathrm{n}=32$ or 36 [19]. These characteristics corroborate the important difference between European and tropical abalones and strengthen the need of specific technical and genetic improvement methods targeted to this species. In western France (Plouguerneau), hatchery techniques for $H$. $t u$ berculata were adapted from [20]. Nowadays, this species is at the first levels of domestication with three generations of mass selection, with a choice of individuals based on morphological traits, and particularly growth rate. Genetic improvement can be efficient with mass selection in early phases of selection [21], but MAS would be more efficient in later stages, or for other traits, as it is now clearly established on several cattle or plant species.

The aim of the present investigation was to study parameters linked to the early stages of abalone development, and to estimate heritability of quantitative traits in this species, which are the first steps of a MAS programs.

\section{MATERIAL AND METHODS}

\subsection{Families Production and Growing Conditions}

\subsubsection{Adult Families}

Adult families were produced in "France Haliotis" hatchery premises in Plouguerneau, and obtained from parents collected from wild stocks in North Western French Brittany (Plouguerneau and Roscoff). Each family was produced from a parental pair and kept in separated nursery tanks for the first year. Crossing experiments were done in individuals baskets to ensure the avoidance of contamination of sperm and egg, or mixing of larvae or juveniles among families. Then the juveniles of the 10 selected families of approximately $20 \mathrm{~mm}$ of maximum length were reared in small sea cages (Figure 1(a)) at about $10 \mathrm{~m}$ below chart datum for 2 years prior to sampling. Each family was reared in separate rearing units at the same density. The sea cages were lifted and the abalone fed every other week with fresh seaweed (mostly Palmaria palmata).

\subsubsection{Juvenile Families}

Juvenile families (Table 1) were produced in 2010 in "France Haliotis" in Plouguerneau, and obtained from parents belonging to the company stock (Table 2). As the objective of the work was to have QTL analyses, the different crosses were done in order to optimize the genetic variability and the phenotypic variability in the progenies. In most cases, an individual belonging to a family representative of big individuals was crossed with an individual belonging to a family representative of small or medium individuals. Moreover, individuals were chosen according to the genetic differences evidenced with the 8 SSR markers developed by [22] with the objective of crossing as genetically different individuals as possible. Twelve full-sib families were thus obtained in May during the reproduction period, and were issued from the 10 full-sib families previously as

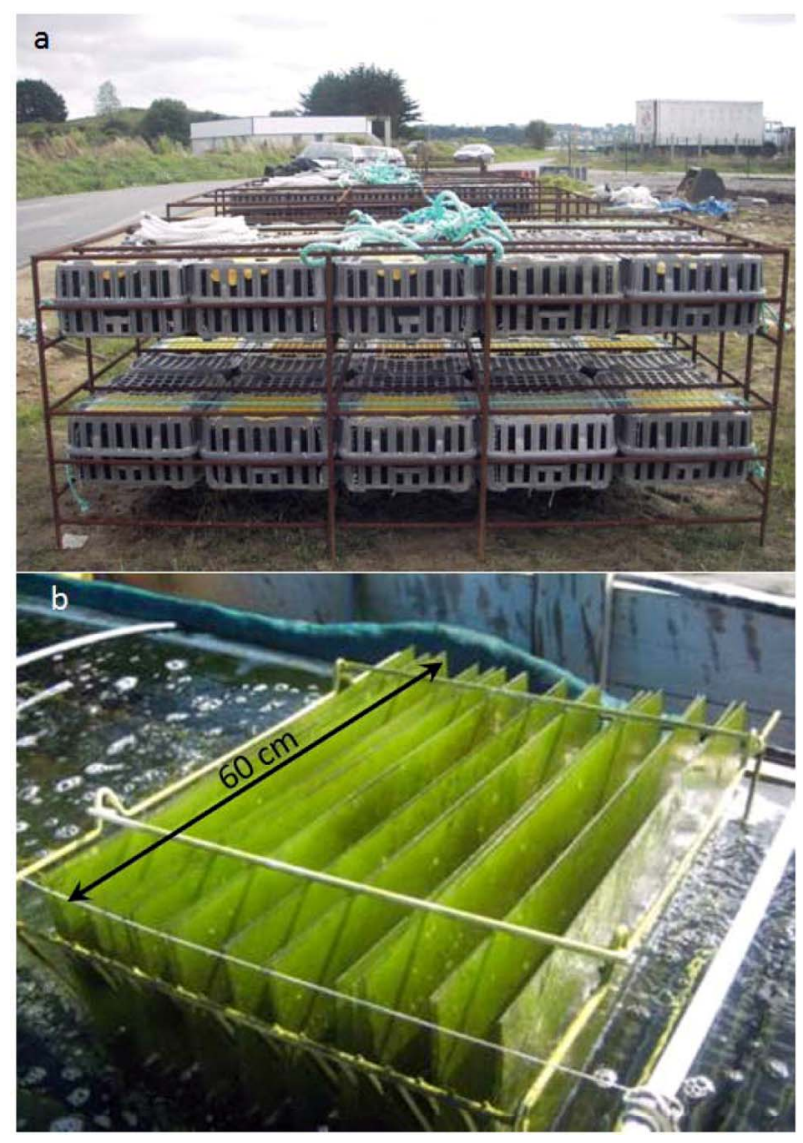

Figure 1. Cages (a) and juvenile plates (b) used for rearing the families. The plates are $60 \mathrm{~cm} \times 60 \mathrm{~cm}$. 
Table 1. Genitors selected for each of the 12 juvenile families, and size of their shells length. A2 to A8 corresponds to genitors presents in the company stock, and wild parents correspond to genitors coming from the Plouguerneau Coast in North Brittany.

\begin{tabular}{ccc}
\hline Juvenile Family & Crossing & Size $(\mathrm{cm})$ \\
\hline J1 & Wild $\times$ A6 & $6.2 \times 6.7$ \\
J2 & A6 $\times$ A8 & $5.9 \times 6.3$ \\
J3 & A3 $\times$ A4 & $6.8 \times 5.9$ \\
J4 & A5 $\times$ A3 & $5.8 \times 6.7$ \\
J5 & A3 $\times$ A8 & $5.8 \times 6.7$ \\
J6 & A3 $\times$ Wild & $6.4 \times 6.7$ \\
J7 & A6 $\times$ A2 & $6.4 \times 6.6$ \\
J8 & A1 $\times$ A2 & $6.1 \times 6.2$ \\
J9 & A3 $\times$ A6 & $6.3 \times 6.1$ \\
J10 & A3 $\times$ A2 & $5.6 \times 6.6$ \\
J11 & A3 $\times$ A8 & $5.8 \times 6.0$ \\
J12 & A6 $\times$ A2 & $6.8 \times 6.6$ \\
\hline
\end{tabular}

previously described. Each of these juvenile families was disposed in a separate tank. All tanks comprised six baskets containing 20 plates each (Figure 1(b)), covered with Ulvella lens [20]. The juveniles were feed with Palmaria palmata, Ulva lactuca, and Saccharina saccharina.

\subsection{Sampling, DNA Extraction and Genotyping of Adult Families}

Thirty individuals were randomly chosen from the 10 adult families. An epipodial clip was taken from each individual and conserved in 70\% ethanol for DNA extraction. DNA was extracted with the CTAB method [23], and was used to characterized COI mtDNA as previously described [24], and to amplify eight microsatellite loci in two quadriplex, as described in [22]. These loci are highly polymorphic and some of them present null alleles. Amplified products were diluted in formamide containing GENESCAN-350(ROX) (Applied Biosystem) size standard, and size polymorphisms were screened using an ABI Prism 3130 DNA sequencer (Applied Biosystem). DNA fragments were analyzed using Genemapper software version 4.0 (Applied biosystem).

\subsection{Trait Evaluation for Adult Families}

Direct measurements of length, width and weight were performed on three years old animals.

Condition factor [25] was calculated using:

$$
\mathrm{CF}=\frac{\text { weight }(g)}{\text { length }(\mathrm{mm})^{2.99}} \times 5575
$$

To evidence the color characteristics of the shells, and study the correlation between these characteristics and genetic parameters, one photograph of the entire outer shell of each abalone was taken using an Olympus Camedia C400 in a room of "France Haliotis" hatchery. Yelow color was chosen as background color after pre-
Table 2. Number of individuals studied for each step of the work (N: number of individuals by sampled; $n$ : number of individuals genotyped; $\mathrm{n}_{\mathrm{p}}$ : number of individuals used for phenotypic traits, $\mathrm{n}_{\mathrm{c}}$ : number of individuals used for color traits).

\begin{tabular}{ccccc}
\hline Adult Family & $\mathrm{N}$ & $\mathrm{n}$ & $\mathrm{n}_{\mathrm{p}}$ & $\mathrm{n}_{\mathrm{c}}$ \\
\hline A1 & 30 & 0 & 0 & 0 \\
A2 & 30 & 27 & 27 & 26 \\
A3 & 30 & 25 & 25 & 22 \\
A4 & 30 & 23 & 23 & 20 \\
A5 & 30 & 0 & 0 & 0 \\
A6 & 30 & 26 & 26 & 19 \\
A7 & 30 & 25 & 25 & 24 \\
A8 & 30 & 24 & 24 & 19 \\
A9 & 30 & 27 & 27 & 17 \\
A10 & 30 & 0 & 0 & 0 \\
\hline
\end{tabular}

liminary test. All the pictures were taken during daytime from the morning to the evening, inducing a difference of light intensity. This effect was eliminated by using appropriate color spaces components which did not take in account this phenomenon and allow to work on independent traits like: $\mathrm{Cb}$ (blue) and $\mathrm{Cr}$ (red) from YCbCR color space, and $\mathrm{H}$ (Hue) from HSV color space (the value of red and blue is included between 0 and 255, and hue value between 0 and 359). These pictures were treated by using classical methods of image processing (Figure 2). A binary image was obtained by using Otsu's threshold method [26], and then, the background was separated from the area of interest to exclude the non-animal part of the picture.

Next step of processing is cleaning of organisms attached to the shell (tags, algae, or small shellfishes), using mathematical morphology tools, which could biased the result of color analysis processing. These processes produced a binary cleaned image of the abalone. In fine, this image was superposed to red, blue and hue picture permitting to exclude pixels of background and parasitic element of shell. The result was the selection and value of pixels of interest. The three averages of components were calculated. For the images programming, all the calculations were conduced with the software Octave (http://www.gnu.org/software/octave/).

\subsection{Trait Evaluation for Juvenile Families}

During the last stage of biological development, the relationship between growth and density on the plates was studied. For that, the density and size of individuals were determined at 90 days after fecundation for the 12 families. For each family, 120 individuals were evaluated on 6 different plates of $3600 \mathrm{~cm}^{2}$, to estimate the variability of the density. For each plate, individual size was measured on 20 individuals.

\subsection{Data Analysis}

For parentage assignment, a chi-square test was perfor- 


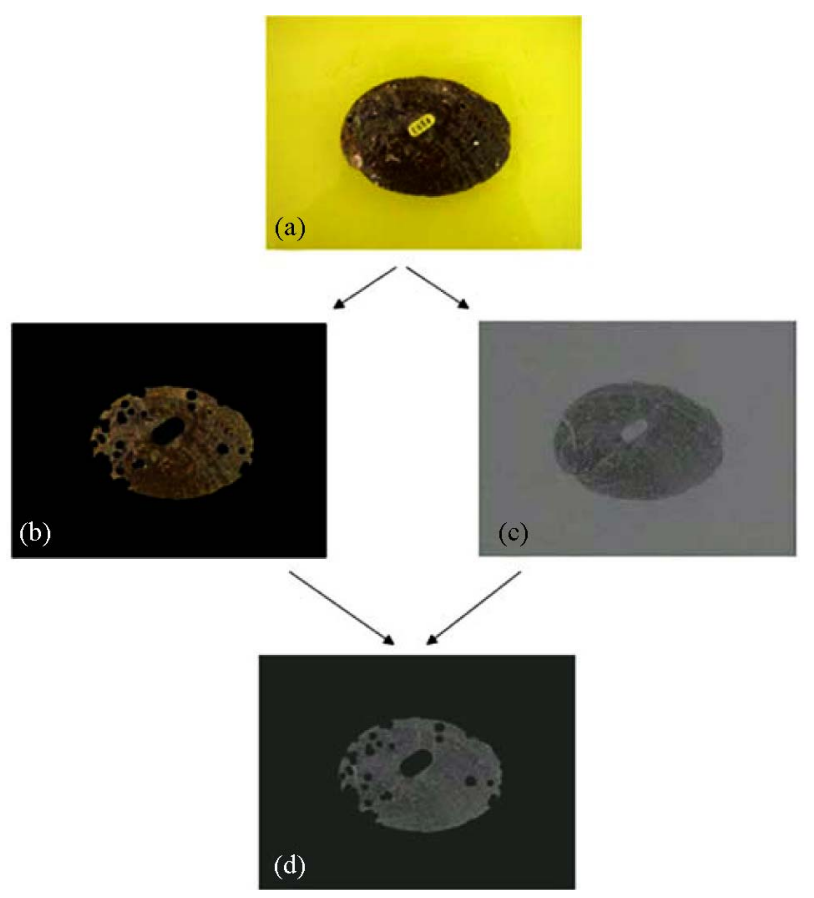

Figure 2. Image treatment of the abalone pictures: (a) Initial picture; (b) Threshold picture (with the background to 0); (c) Red levels of the picture; (d) Final picture.

med to verify if the allelic frequencies observed in a family were in accordance with those expected in theory.

Analysis of variance were carried out following the standard procedure of a fixed model with only the family effect for adult and with family and density effect for juveniles. Densities were ranked into 8 classes from 20 to 548 animals per plate.

For adults: $\mathrm{Yi}=\mu+\mathrm{F}_{\mathrm{i}}+\mathrm{e}_{\mathrm{i}}$

For juveniles: $\mathrm{Yij}=\mu+\mathrm{F}_{\mathrm{i}}+\mathrm{D}_{\mathrm{j}}+\mathrm{F}_{\mathrm{i}} \cdot \mathrm{D}_{\mathrm{j}}+\mathrm{e}_{\mathrm{ij}}$

With $\mu=$ Grand mean, $\mathrm{F}_{\mathrm{i}}=$ Family effect, $\mathrm{D}_{\mathrm{j}}=$ Density effect, $F_{i} \cdot D_{j}=$ Density within Family nested effect, and $\mathrm{e}=$ residual error.

For both groups (adults and juveniles) and trait, full-sib heritability and its standard deviations was calculated after analysis of variance according to Falconer (1989) as described in [27]:

$$
h_{F S}=\frac{\left(V_{A}+1 / 2 V_{D}+1 / 2 V_{I}+2 V_{C E}\right)}{V_{p}}
$$

with

$V_{A}, V_{D}, V_{I}, V_{E C}$ and $V_{P}$ : Additive, Dominant, Epistatic, Error and total phenotypic variance respectively.

$$
\begin{gathered}
h_{F S}=\frac{2 V_{F}}{V_{P}} \\
h_{F S}=\frac{2 \sigma_{F}^{2}}{\sigma_{F}^{2}+\sigma_{w}^{2}}
\end{gathered}
$$

and

$$
\sigma h_{F S}=2\left(\frac{2(1+(n-1) t) ?}{n(n-1)(N-1)}\right)^{1 / 2}
$$

with:

$h_{F S}$ : Full Sub heritability for each trait

$\sigma_{F}^{2}$ : variance between the progeny of different families

$\sigma^{2}$ : variance between the individuals within a family

$n$ : number of offspring per family ( $=24$ for morphological traits and $=19$ for color traits)

$N$ : number of families

$t$ : full-sib interclass correlation $\left(=1 / 2 h_{F S}\right)$

For juveniles, an analysis of covariance was performed to test the relationship between individual size and density on the plate. Correlation study and one way full-sib analysis of variance with family as the main effect were performed using the $R$ software package (http://cran.r-project.org/).

\section{RESULTS}

\subsection{Adult Families}

\subsubsection{Family Assignment}

Two individuals from each family were randomly chosen and analyzed with $\mathrm{COI}$ and sperm lysin gene, evidencing that all were of $H$. t. tuberculata subspecies (data not shown). For each family, all progeny of 30 randomly chosen individuals was studied with SSR following three steps. The first one corresponds to the elimination of families which present more than four alleles with high frequency. As we want to work on bi-parental families, each parent can bring a maximum of two alleles, and as this species is diploid and as the SSR markers used were known to amplify a non duplicated portion of the genome [22] the progeny must present a maximum of four different alleles. Three families $(30 \%)$ with too many major alleles were eliminated. The second step corresponds to the elimination of individuals which brings alien alleles, never (or rarely) presents in other individuals. This strategy has allowed the elimination of individuals without parentage relationship with the others (10 to $16.6 \%$ of the progeny). And the last step corresponds to the elimination of individuals which possess the same alleles than the major ones, but which present an association not compatible with the parental genotypes found ( $0 \%$ to $6 \%$ of the progeny). For the seven bi-parental families (excluding the pluri-parental families), the number of full-sib individuals ranged from 23 to $27(76.6 \%$ to $90 \%)$ after the elimination of foreign individuals evidenced with the SSR markers. None of the families have common parent.

\subsubsection{Heritabilities}

1) Morphological Traits

All three investigated morphological traits and the two 
color traits showed a high variability (Figure 3 ) even in some of cases, the difference between families seemed less important (length/width, and condition factor). Three families presented high values for shell length and width traits: A2, A6 and A4, while four families had lower values: A9, A8, A7 and A3. For weight trait, the highest values were observed for A2 and A6 families and lowest values for $\mathrm{A} 7$ and $\mathrm{A} 3$ families. Heritability estimates are shown in Table 3 where the highest values are found for weight, length and width $(0.40,0.37$, and 0.29 , respectively). Condition factor and length/width presented low heritability values ( 0.12 and 0.02 respectively), probably linked to a non normality: the ratio between two normal characters is non normal.

Distribution of the three more heritable traits and correlations between these traits are given in Figure 4. The normal distribution of these traits was tested with a Shapiro test, and evidenced normality for all the mor-
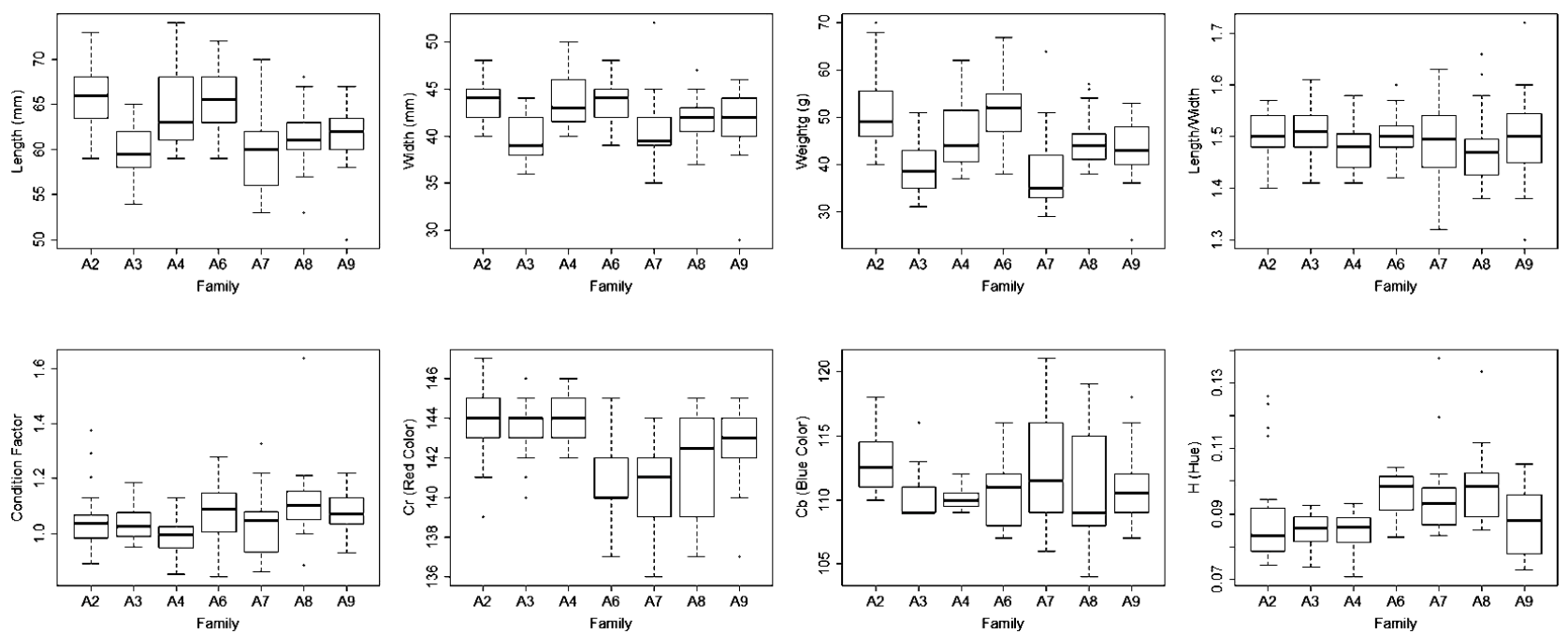

Figure 3. Box plots of the different traits for each adult family.

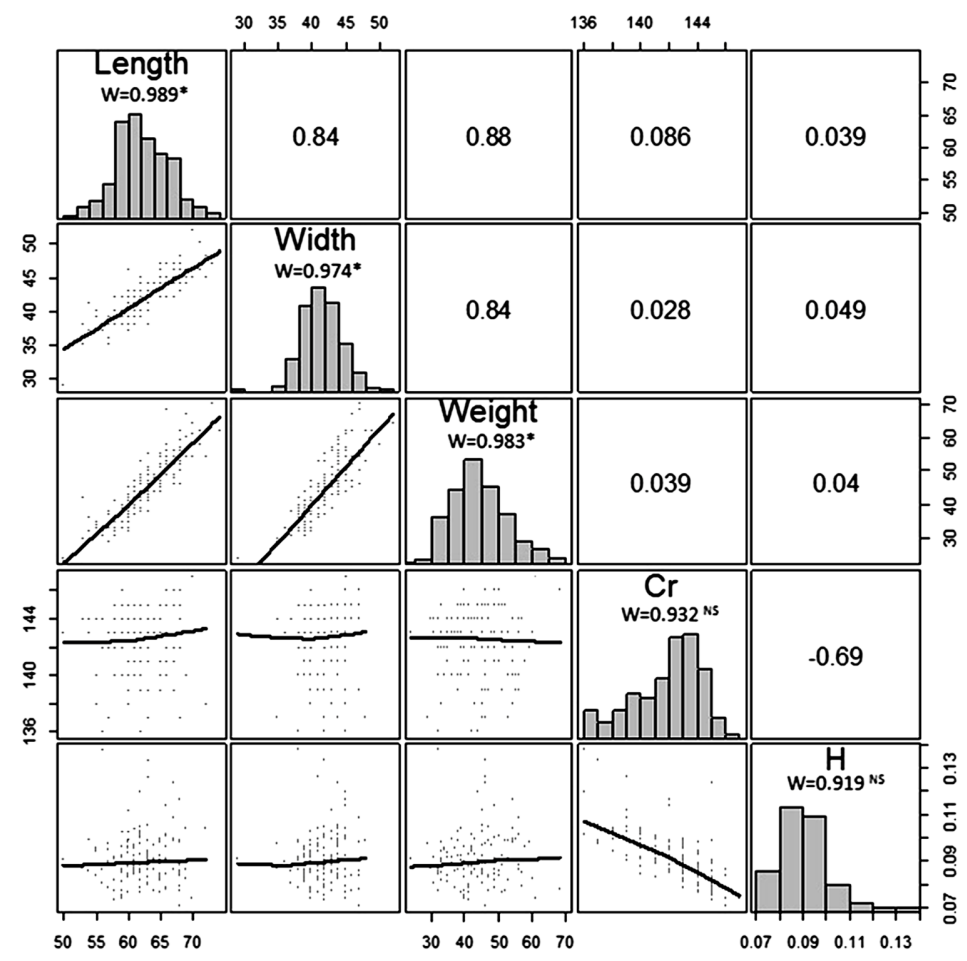

Figure 4. Correlations and distribution of the five traits presenting the highest heritability values. For each trait, the $\mathrm{W}$ value for Shapiro test is indicated $\left({ }^{*}\right.$ significant at $0.001 ;{ }^{\mathrm{NS}}$ non significant). 
phological traits. A high correlation (ranging from 0.84 to 0.88 ) between them was also evidenced, the most important one was found between weight and length.

\section{2) Color Traits}

As some visual observations in the natural environment seem to indicate that the red abalones are taller and heavier than the others, we decided to investigate color parameters. For that, most of the individuals (Table 2) were also used to be described with image treatments. We do not observe different colors, but only one (redbrown) with different intensities. Two color traits (red color: $\mathrm{Cr}$, and Hue: H) presented a high variability (Figure 3 ).

These traits presented a low heritability with $\mathrm{h}^{2}$ value of 0.33 and 0.2 respectively (Table 3 ). The correlation between these two traits was equal to 0.69 (Figure 4). However, no correlation was shown between morphological and color traits. The blue color $(\mathrm{Cb})$ presented a low variability and heritability.

\subsection{Juvenile Families}

The results on size and density on the plates is represented on Figure 5 and evidenced a high variability between families. Five of them presented an important size $(\mathrm{J} 1, \mathrm{~J} 3, \mathrm{~J} 5, \mathrm{~J} 7$ and J9) and the other five presented a lower size (J4, J6, J8, J11 and J12). For density, the number of animals per $3600 \mathrm{~cm}^{2}$ presented a lower variability between families and a higher level of intra-family variability. The correlation and covariance between these two parameters evidenced a negative link $(r=-0.45, \operatorname{cov}=-45.15)$ between size and density. Size heritability for juveniles was calculated and presented a high value of 0.74 .

\section{DISCUSSION}

\subsection{Adult Family Assignment}

Our results showed that the assignment of individuals after crossing in hatchery is necessary. Due to the high number of crossing it is not excluded that fertilization of eggs with sperm coming from different individuals may occur. It was the case in three progenies among the 10 selected. In this study, it was important to determine the genetic relationship between individuals of the progenies. During the nursery period, small larvae are cultivated on patches in the same tank. Even is the power of dispersal is low for the larvae, a mix between families is also possible at this step.

The adult growth conditions includes an opening of the cages and in most of the cases, some abalones can be taken out theses cages during the bringing of fresh seaweeds. In such conditions, a mix between some adult individuals is also possible. The aim of the parental as-
Table 3. Heritability $\left(\mathrm{H}^{2}\right)$ and its standard deviation $\left(\sigma \mathrm{H}^{2}\right)$ for all traits studied. For Adult families: CF: Condition Factor, L/W: Length/Width, Cr: red color, Cb: blue color; H: Hue. For Juvenile families: SizeJuv: Size of the shell.

\begin{tabular}{ccc}
\hline Trait & $\mathrm{H}^{2}$ & $\sigma \mathrm{H}^{2}$ \\
\hline Length & 0.37 & 0.11 \\
Width & 0.29 & 0.07 \\
Weight & 0.40 & 0.13 \\
$\mathrm{CF}$ & 0.12 & 0.02 \\
$\mathrm{~L} / \mathrm{W}$ & 0.02 & 0.00 \\
$\mathrm{Cr}$ & 0.33 & 0.09 \\
$\mathrm{Cb}$ & 0.08 & 0.01 \\
$\mathrm{H}$ & 0.20 & 0.04 \\
Sizejuv & 0.51 & 0.18 \\
\hline
\end{tabular}

signment was to select only the real full-sib progeny of each family. But, as the genitors were not available, we had to determine their genotypes from those of their progeny.

Whereas it was shown the presence of Haliotis tuberculata coccinea COI signature in high proportion in French Brittany [24] the analysis of this marker indicated that all the analyzed individuals were of "tuberculata" sub-species. SSR analysis confirmed the absence of $H$. $t$. coccinea in French Brittany. This was important to highlight because nobody has tested the growth performances of the two sub-species and the putative role of mitochondrial introgressed genomes in French Brittany.

Microsatellite markers were evidenced to be efficient for parentage assignment in different species like common carp [28] for which eight microsatellites were used to assign parentage in a full factorial cross of 10 dams and 24 sires, the shrimp Penaeus japonicus [29] for which eight microsatellites loci were used to discriminate 864 shrimp progeny originated from four ponds, abalone Haliotis asinina [30] for which five polymorphic loci were successfully used to assign parentage to young larvae, and for adult individuals [31].

In our case, as the parents genotypes were not known, the only solution to be sure of the common origin of the progenies was to choose only full-sib individuals. In fact, it the case of multi-parental progenies, the segregation of individuals would be impossible without the parental genotypes as start point. That is why the first step of the study was to select only bi-parental families where the number of alleles was reduced. The next steps corresponding to the elimination of foreign individuals with the study of allelic frequencies and genotype analysis permit to select only the effective progeny of the parents previously genotyped. This method is efficient to define parentage assignment when the genitors genotypes are not known but when the study of families without foreign individuals is necessary, like in heritability studies. 

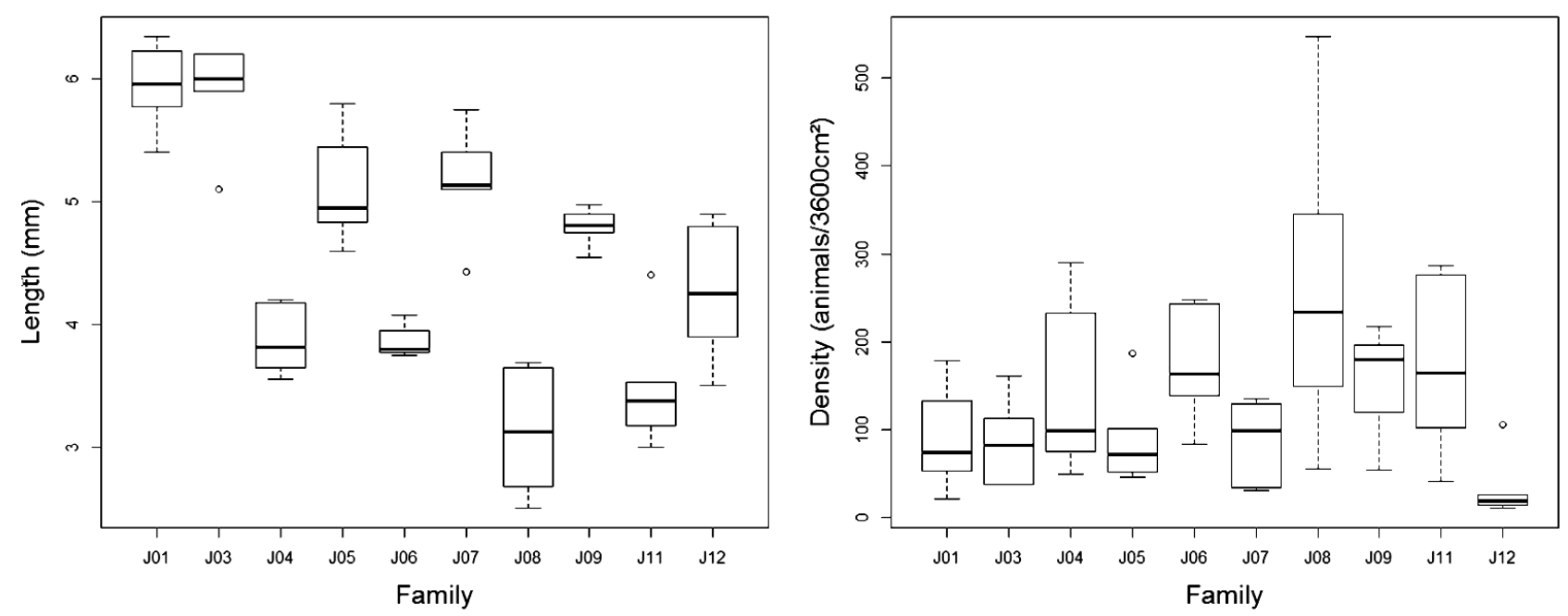

Figure 5. Box plots of length and density for each juvenile family. Size was measured after 90 days on 120 individuals. Adult families from which they corresponded are indicated in Table 1.

\subsection{Heritabilities}

All the studied traits present a moderate to high diversity. For instance, no markers assisted selection (MAS) programs exist for European abalone. The first step of such programs, correspond to the identification of the traits which can be improved by selection, by studying their heritabilities. This work was done for several morphological or color traits, which can be of interest in selection. Our study was done on breeding conditions, by using families selected in a farm. Higher the heritability is, and higher and easier the potential of improvement is. In general, we consider that traits which present an heritability value equal or superior to 0.2 can be useful for selection, and can be improved during a breeding program [32]. These results were obtained in a commercial environment, so they can be used directly for improvement programs. But according to this mating system, the calculation of heritability allow to obtain a broad-sense heritability, taking in account all the genetic parameters, contrarily to the narrow-sense heritability, taking in account only the additive effects of the traits and leading to a finer estimate of the heritability for breeding purposes. Finer results could be obtained with another mating design, like the "Full Factorial Design with Few Dams" which was evidenced to be superior to other ones [33] and could give access to the narrow-sense heritability.

Heritabilities obtained for weight (0.40) appear to be comparables to those obtained for Haliotis asinina [31] which presents a weight heritability equal to 0.36 . Shell length and width presents heritabilities of 0.37 and 0.29 respectively which is comparable to the results obtained with Haliotis discus hannai (0.36 and 0.32 respectively, [34]) or Haliotis rufescens for which an heritability of 0.34 was evidenced for shell length [35], but our result seems to be lower than the one obtained for Haliotis asinina shell length which was of 0.48 [31]. Concerning the shell morphology, it has been shown that heritability varies during animal development and becomes higher at the adult stage [35-37]. Consequently, for improving these traits, it would be better to use 24 months values. As the correlation between the three traits is very high, the weight can likely be improved by selecting for shell size.

The ratio length/width and the Condition Factor presents a low value of heritability, which can be linked to the high values of intra-family variability, and to the non normality of the characters. As the heritability calculation takes into account the variability at the intra and inter-family level, when the first value is higher, the value of heritability is lowered (in this case, the intra-family variability is equal to $25 \%$ and $65 \%$ of the inter-family variability, for each of the two traits, respectively).

Some previous studies concerning the shell color were done for Haliotis discus hannai [38,39] evidencing the monogenic genetic control of the shell color variation in this species presenting different colors (green, blue or orange). The Mendelian segregation of the progenies indicated that the color variant types were controlled by a single locus presenting a recessive and a dominant allele. As the shell color for Haliotis discus hannai is a monogenic trait, the objective of the color study was to have information about genetic determinism of shell color in Haliotis tuberculata for witch some observations at the farm seemed to suspect the red shelled individuals to be taller than the others. Contrarily to what was suspected by observations, red ormers are not taller than the others. Consequently, this visual marker can not be used for an easy improvement of European abalones. As the shell color character presents a non normal distribution, it 
seems to be highly influenced with environmental factors, so, for European abalone, the genetic control of the shell color seems to be different than the one previously observed for Haliotis discus hannai. It has been shown that the abalone diet could modify the shell color [39], that is why all the studied animals were feed with the same fresh algal diet, mostly Palmaria palmata, Ulva lactuca and Laminaria digitata, the ones which are usually consumed by the wild abalones during the study to avoid the expression of colors linked to the diet and thus, limit the environmental effect for the studied trait.

Concerning Haliotis tuberculata, contrarily to other species, shell color present only different variations of $\mathrm{red} / \mathrm{brown}$, that is why we only studied the red color and the hue. Other colors were not representative, and intensity or saturation could not be representative because of absence of variability linked to the shell characteristics of our model. The high value of the correlation between the two traits indicates that the red color is the majority represented color in the shell panel.

Contrarily to Haliotis discus hannai [38,39], no mendelian segregation could be evidenced in our progenies, but the observed distribution (Figure 4) evidenced a role of environmental conditions. If such a genetic control was not evidenced before in abalone species, it is not the case for another molluscan species like oyster [40,41]. These studies evidenced a polygenic control of the extern shell pigmentation like in Crassostrea gigas with the implication of one major gene in this trait.

\subsection{Juvenile Improvement}

For Rodriguez [42], settlement is a process comprising two phases: 1) a phase of searching for a suitable substratum, and 2) a phase of attachment and metamorphosis. These parametres were excluded from our study because they were controled in the Hatchery. At the fixation stage, it was not possible to evidence a significant role of water temperature on fixation rate. In all cases $\left(14\right.$ to $\left.22^{\circ} \mathrm{C}\right)$, this rate is always very variable and no temperature appears to bring better results than others. At this stage, numerous environmental variables can be involved in fixation rate, like algal composition on the plates [43].

At the benthic stage, we observed a negative link between the size of animals and the density, probably because of the limited food on the plate. Moreover, due to the limited number of crossing adressed for this experiment, the asignment of the descendance was not necessary. The high heritability for the size $(0.74)$ is probably due to 1) the elimination of the density parameter, and 2) the fact that for juvenile, we have less environmental parameters to take in account compared with adult animals. It will be now important to study the correlation between juvenile size and adult size. If this parameter is high, it will be possible in the future, to select families at a juvenile stage without waiting the animals to be adults.

\section{CONCLUSION}

Concerning shell color, contrarily to the Pacific abalone, European abalone does not present a monogenic control of this trait even if we could observe a major color (red). This trait is not related to growth parameters. This study brings other useful information about the European abalone selection, particularly for biological traits like weight and shell size, evidencing the high correlation between these traits and their high broad-sense heritability which indicates that a selection could be effective for such traits. This high heritability value was also evidenced in juvenile families of 90 days and on adults.

\section{ACKNOWLEDGEMENTS}

This work was supported by EC (SUDEVAB No. 222156 "Sustainable development of European SMEs engaged in abalone aquaculture"). The authors would like to thank Yves Barrière for its helpful and constructive comments to improve the manuscript.

\section{REFERENCES}

[1] Coleman, A.W. and Vacquier, V.D. (2002) Exploring the phylogenetic utility of ITS sequences for animals: A test case for abalone (Haliotis). Journal of Molecular Evolution, 54, 246-257. doi:10.1007/s00239-001-0006-0

[2] Fleming, A.E. and Hone, P.W. (1996) Abalone aquaculture. Aquaculture, 140, 1-4. doi:10.1016/0044-8486(95)01183-8

[3] Hahn, K. (1989) Nutrition and growth of abalone. In: Handbook of Culture of Abalone and Other Marine Gastropods, CRC Press, Boca Raton, 135-180.

[4] Britz, P.J., Hecht, T. and Mangold, S. (1997) Effect of temperature on growth, feed consumption and nutritional indices of Haliotis midae fed a formulated diet. Aquaculture, 152, 191-203. doi:10.1016/S0044-8486(97)00002-1

[5] Elliott, N.G. (2000) Genetic improvement programmes in abalone: what is the future? Aquaculture Research, 31, 51-59. doi:10.1046/j.1365-2109.2000.00386.x

[6] Elliott, N.G., Evans, B., Conod, N., Bartlett, J., Officer, R. and Sweijd, N. (2000) Application of molecular genetics to the understanding of abalone population structureAustralian and South African case studies. Journal of Shellfish Research, 19, 510.

[7] Grubert, M.A. and Ritar, A.J. (2005) The effect of temperature and conditioning interval on the spawning success of wild-caught blacklip (Haliotis rubra, Leach 1814) and greenlip (H. laevigata, Donovan 1808) abalone. Aquaculture Research, 36, 654-665. doi:10.1111/j.1365-2109.2005.01269.x

[8] Braid, B.A., Moore, J.D., Robbins, T.T., Hedrick, R.P., Tjeerdema, R.S. and Friedman, C.S. (2005) Health and survival of red abalone, Haliotis rufescens, under varying temperature, food supply, and exposure to the agent of 
withering syndrome. Journal of Invertebrate Pathology, 89, 219-231. doi:10.1016/i.jip.2005.06.004

[9] Lymbery, A.J. (2000) Genetic improvement in the Australian aquaculture industry. Aquaculture Research, 31, 145-149. doi:10.1046/j.1365-2109.2000.00435.x

[10] Roodt-Wilding, R. (2007) Abalone ranching: A review on genetic considerations. Aquaculture Research, 38, 12291241. doi:10.1111/j.1365-2109.2007.01801.x

[11] Liu, X., Liu, X., Guo, X., Gao, Q., Zhao, H. and Zhang, G. (2006) A preliminary genetic linkage map of the pacific abalone Haliotis discus hannai Ino. Marine Biotechnology, 8, 386-397. doi:10.1007/s10126-005-6133-7

[12] Qi, L., Yanhong, X., Ruihai, Y. and Akihiro, K. (2007) An AFLP genetic linkage map of pacific abalone ( $\mathrm{Ha}$ liotis discus hannai). Journal of Ocean University of China (English Edition), 6, 259-267. doi:10.1007/s11802-007-0259-3

[13] Sekino, M. and Hara, M. (2007) Linkage maps for the Pacific abalone (genus haliotis) based on microsatellite DNA markers. Genetics, 175, 945-958. doi:10.1534/genetics.106.065839

[14] Baranski, M., Loughnan, S., Austin, C.M. and Robinson, N. (2006) A microsatellite linkage map of the blacklip abalone, Haliotis rubra. Animal Genetics, 37, 563-570. doi:10.1111/j.1365-2052.2006.01531.x

[15] Huchette, S. and Clavier, J. (2004) Status of the ormer (Haliotis tuberculata L.) industry in Europe. Journal of Shellfish Research, 23, 951-955.

[16] Hayes, B., Baranski, M., Goddard, M.E. and Robinson, N. (2007) Optimisation of marker assisted selection for abalone breeding programs. Aquaculture, 265, 61-69. doi:10.1016/j.aquaculture.2007.02.016

[17] Wagner, R. and Abbott, R. (1967) Van Nostrand's standard catalog of shells. V.N. Company, Princeton.

[18] Girard, A.(1972) La reproduction de l'ormeau Haliotis tuberculata L. Rev. Trav. Inst. Pêches Marit., 36, 163184.

[19] Geiger, D.L. and Groves, L.T. (1999) Review of fossil abalone (Gastropoda, Vetigastropoda, Haliotidae) with comparison to recent species. Journal of Paleontology, 73, 872-885.

[20] Daume, S., Huchette, S., Ryan, S. and Day, R.W. (2004) Nursery culture of Haliotis rubra: The effect of cultured algae and larval density on settlement and juvenile production. Aquaculture, 236, 221-239. doi:10.1016/j.aquaculture.2003.09.035

[21] Bentsen, H.B. and Olesen, I. (2002) Designing aquaculture mass selection programs to avoid high inbreeding rates. Aquaculture, 204, 349-359. doi:10.1016/S0044-8486(01)00846-8

[22] Roussel, V., Huchette, S. and Van Wormhoudt, A. (2010) Isolation and characterization of eight microsatellite loci in the European abalone, Haliotis tuberculata. Molecular Ecology Resources, 10, 751-754.

[23] Doyle, J.J. and Doyle, J.L. (1987) A rapid isolation procedure for small quantities of fresh leaf tissue. Phytochemistry Bulletin, 19, 11-15.
[24] Van Wormhoudt, A., Le Bras, Y. and Huchette, S. (2009) Haliotis marmorata from Senegal; A sister species of Haliotis tuberculata: Morphological and molecular evidence. Biochemical Systematics and Ecology, 37, 747755. doi:10.1016/j.bse.2009.12.020

[25] Britz, P. J. (1996) The suitability of selected protein sources for inclusion in formulated diets for the South African abalone, Haliotis midae. Aquaculture, 140, 63-73. doi:10.1016/0044-8486(95)01197-8

[26] Otsu, N. (1979) A threshold selection method from graylevel histograms. IEEE Transactions on Systems, Man and Cybernetics, 9, 62-66. doi:10.1109/TSMC.1979.4310076

[27] Garenc, C., Silversides, F.G. and Guderley, H. (1998) Burst swimming and its enzymatic correlates in the threespine stickleback (Gasterosteus aculeatus): Full-sib heritabilities. Canadian Journal of Zoology, 76, 680-688.

[28] Vandeputte, M., Kocour, M., Mauger, S., Dupont-Nivet, M., De Guerry, D., Rodina, M., Gela, D., Vallod, D., Chevassus, B. and Linhart, O. (2004) Heritability estimates for growth-related traits using microsatellite parentage assignment in juvenile common carp (Cyprinus carpio L.). Aquaculture, 235, 223-236. doi:10.1016/j.aquaculture.2003.12.019

[29] Jerry, D.R., Preston, N.P., Crocos, P.J., Keys, S., Meadows, J.R.S. and Li, Y.(2006) Application of DNA parentage analyses for determining relative growth rates of Penaeus japonicus families reared in commercial ponds. Aquaculture, 254, 171-181.

doi:10.1016/j.aquaculture.2005.10.035

[30] Selvamani, M.J.P., Degnan, S.M. and Degnan, B.M. (2001) Microsatellite genotyping of individual abalone larvae: Parentage assignment in aquaculture. Marine Biotechnology, 3, 478-485. doi:10.1007/s1012601-0062-X

[31] Lucas, T., Macbeth, M., Degnan, S.M., Knibb, W. and Degnan, B.M. (2006) Heritability estimates for growth in the tropical abalone Haliotis asinina using microsatellites to assign parentage. Aquaculture, 259, 146-152. doi:10.1016/j.aquaculture.2006.05.039

[32] Newkirk, G.F., Haley, L.E., Waugh, D.L. and Doyle, R. (1977) Genetics of larvae and spat growth rate in the oyster Crassostrea virginica. Marine Biology, 41, 49-52. doi:10.1007/BF00390580

[33] Dupont-Nivet, M., Vandeputte, M. and Chevassus, B. (2002) Optimization of factorial mating designs for inference on heritability in fish species. Aquaculture, 204, 361-370. doi:10.1016/S0044-8486(01)00839-0

[34] Deng, Y., Liu, X., Zhang, G. and Zhao, H. (2007) Genetic parameter estimates for growth traits at early stage of $\mathrm{Pa}$ cific abalone, Haliotis discus hannai Ino. Acta Oceanologica Sinica, 26, 90-95.

[35] Jonasson, S. and Stefansson, S.E. (1999) Genetic variation for survival and shell length of cultured red abalone (Haliotis rufescens) in Iceland. Journal of Shellfish Research, 1, 621-625.

[36] You, W.-W., Ke, C.-H., Luo, X. and Wang, D.-X. (2009) Divergent selection for shell length in two stocks of small 
abalone Haliotis diversicolor. Aquaculture Research, 41, 921-929. doi:10.1111/j.1365-2109.2009.02376.x

[37] You, W., Ke, C., Luo, X. and Wang, D. (2010) Heritability of growth traits for small abalone Haliotis diversicolor estimated from sib matings. Journal of Shellfish Research, 29, 705-708. doi:10.2983/035.029.0322

[38] Kobayashi, T., Kawahara, I., Hasekura, O. and Kijima, A. (2007) Genetic control of bluish shell color variation in the Pacific abalone, Haliotis discus hannai. Journal of Shellfish Research, 23, 1153-1156.

[39] Liu, X., Liu, X. and Zhang, G. (2007) Identification of quantitative trait loci for growth-related traits in the Pacific abalone Haliotis discus hannai Ino. Aquaculture Research, 38, 789-797. doi:10.1111/j.1365-2109.2006.01647.x

[40] Evans, S., Camara, M.D. and Langdon, C.J. (2009) Heritability of shell pigmentation in the Pacific oyster,
Crassostrea gigas. Aquaculture, 286, 211-216. doi:10.1016/j.aquaculture.2008.09.022

[41] Brake, J., Evans, F. and Langdon, C. (2004) Evidence for genetic control of pigmentation of shell and mantle edge in selected families of Pacific oysters, Crassostrea gigas. Aquaculture, 229, 89-98. doi:10.1016/S0044-8486(03)00325-9

[42] Rodriguez, S.R., Ojeda, F.P. and Inestrosa, N.C. (1993) Settlement of benthic marine invertebrates. Marine ecology progress series. Oldendorf, 97, 193-207.

[43] Courtois de Viçose, G., Viera, M., Bilbao, A. and Izquierdo, M. (2010) Larval settlement of Haliotis tuberculata coccinea in response to different inductive cues and the effect of larval density on settlement, early growth, and survival. Journal of Shellfish Research, 29, 587-591. doi:10.2983/035.029.0306 